\title{
Fabrication of Drug-Loaded Starch-based Nanofibers via Electrospinning Technique
}

\author{
Khairool Azhar Tuah ${ }^{1}$, Suk-Fun Chin ${ }^{1, *}$, Suh-Chem Pang ${ }^{1}$ \\ 1 Faculty of Resource Science and Technology, Universiti Malaysia Sarawak 94300, Kota Samarahan, Sarawak, Malaysia \\ * Correspondence: sfchin@unimas.my;
}

Scopus Author ID 16644797900

Received: 9.10.2020; Revised: 7.11.2020; Accepted: 10.11.2020; Published: 15.11.2020

\begin{abstract}
This paper reported the fabrication of starch-based nanofibers derived from various weight ratios (w:w) of native sago starch (SS) and poly (vinyl alcohol) (PVA) (0:100, 1:100, 3:100, and 5:100) using the electrospinning technique. The effects of electrospinning operation parameters on the surface morphology of SS/PVA nanofibers were observed by using Scanning Electron Microscopy (SEM). The smooth and bead-free SS/PVA nanofibers with fiber diameters within the range of $90 \mathrm{~nm}$ to $150 \mathrm{~nm}$ were produced under the optimized conditions. The paracetamol (PCM) was encapsulated into the SS/PVA nanofibers via the blending process. The SS/PVA nanofibers exhibited a maximum PCM loading capacity of $0.9573 \mathrm{mg} \cdot \mathrm{mg}^{-1}$, and PCM was observed to release out from SS/PVA nanofibers slowly and steadily for 72 hours.
\end{abstract}

Keywords: starch; poly (vinyl alcohol); electrospinning; nanofibers; drug nanocarriers.

(C) 2020 by the authors. This article is an open-access article distributed under the terms and conditions of the Creative Commons Attribution (CC BY) license (https://creativecommons.org/licenses/by/4.0/).

\section{Introduction}

There are numerous techniques for the preparation of nanofibers, such as phase separation [1], physical drawing [2], wet chemical reduction method [3], and electrospinning [4]. Phase separation is a versatile technique for the fabrication of microencapsulation and fiber scaffolds in which this technique comprises dissolution, gelation, extraction with different solvents, condensation, and drying in an orderly way. However, the downside of this technique is expensive due to it uses a lot of coagulants, such as ethanol and sodium hydroxide. Apart from phase separation, the drawing technique is also one of the techniques which produced long individual strands of nanofiber [5]. This technique involved the pulling process and followed by the solidification that turned the liquefied spinning material into the solid fibers. However, the setback of this technique is the limited material option. Only viscoelastic substances can undergo substantial deformations, while cohesion was needed to assist the pressures that developed during the pulling process so that the nanofibers can be formed nicely [6].

Among various methods for nanofibers preparation, electrospinning is the most promising as it is a relatively fast, straightforward, simple, cost-effective, and versatile method [7]. The electrospinning method was proven to be able to produce non-woven fibers [8] that were smaller in diameter than fibers fabricated by other methods [9]. Moreover, the electrospinning technique offers the advantage of its adaptability, its consistency in producing multifunctional nanofibers from various polymers ranging from a few micrometers to a few nanometers, and its versatility in spinning a large selection of polymeric fibers. In 2018, Zhang 
et al. [10] reported the successful fabrication of electrospun nanofibers of polyethylene glycol (PEG)-modified poly (lactic-co-glycolic acid) (PLGA) and exhibited a fast release profile for the model drug of amoxicillin (AMX). These electrospun drug-loaded nanofibers have an excellent hemocompatibility and cytocompatibility that was useful for tissue engineering and pharmaceutical applications.

The electrospun starch-based nanofibers have been comprehensively studied due to their desirable properties, which are high surface area to volume ratios [9], high porosity [11], good adhesion, high flexibility, and superior mechanical strength that could be achieved simply by manipulating the electrospinning parameters $[9,12,13]$. Electrospun fibers appeared to be versatile and useful in various applications such as in wastewater treatment, filtration, tissue engineering, wound dressing[11], and drug delivery[4]. Both water-soluble and insoluble polymers have to be blended to produce nanofibers with desirable properties for drug delivery applications [14-16]. Fonseca et al. (2019) had fabricated electrospun potato starch nanofibers loaded with carvacrol with a loading concentration of $40 \%(\mathrm{v} / \mathrm{v})$ and a diameter of $94 \mathrm{~nm}$ [17]. Apart from that, the maize starch acetate (SA) nanofibers have been studied for its potential applications in drug delivery by $\mathrm{Xu}$ et al. [18]. The SA were electrospun from the SA solution using formic acid/water mixture, and diclofenac was loaded as a model drug. Their studies showed that $90 \%$ (v/v) formic acid/water was an optimum solvent system for the production of uniform and fine SA nanofibers.

In recent years, there are increasing numbers of researchers focused on the fabrication of starch-based nanofibers from various starches such as tapioca starch [19], potato starch [20,21], and corn starch [22,23] via the electrospinning technique for various biomedical applications such as wound dressing, tissue engineering, and drug delivery [24] because of its non-toxicity, coupled with excellent physicochemical and biocompatibility. The electrospinning method has been used to produce Chlorpheniramine maleate (CPM) (antihistamine drug) loaded glutinous rice starch (GRS) nanofibers from 2\% (w/v) GRS and $8 \%(\mathrm{w} / \mathrm{v})$ of PVA for drug delivery application[9].

Even though starch nanofibers have been proven to be promising as nanocarriers for various drugs and nutraceutical products because of the various advantages, such as high drug loading capacity, improved drug solubility, and stability [25,26], nonetheless, it comes with a drawback as starch nanofibers were the weak electrospun fiber-forming agent as it is brittle and highly sensitive to moisture. These limitations could be rectified by blending starch with linear chain polymer [11] such as Poly(vinyl alcohol) (PVA) [23] due to PVA exhibited excellent spinnability properties [27]. Furthermore, PVA also has been widely used in the biomedical field as it is a biodegradable, non-toxic, water-soluble, hydrophilic great chemical and thermal stability as well as low acute oral toxicity [28]. According to studied by Šukyte and their research mate, done in the year 2010 showed that starch nanofibers with mean diameter size ranging from $250 \mathrm{~nm}$ to $340 \mathrm{~nm}$ were produced at $65 \mathrm{kV}$ of electrospinning [29]. In addition, in 2012, Lu and her team had also reported the size of the diameter of nanofibers with a mean diameter ranging from 188 to $265 \mathrm{~nm}$ by increasing the concentration of ethanol at $16 \mathrm{kV}$. Ethanol could be one of the factors that influence the size diameter of the nanofibers produced [30].

In this study, we report on the fabrication of starch-based nanofibers with a diameter ranging from $90 \mathrm{~nm}$ to $150 \mathrm{~nm}$ from a native sago starch (SS) and PVA solution using the electrospinning technique. The optimization of various weight ratios of SS/PVA (1:100, 3:100, and 5:100) was carried out to produce smooth and bead-free starch-based nanofibers via the 
electrospinning approach. Then fabricated SS/PVA nanofibers were characterized using Scanning Electron Microscope (SEM), Fourier Transform Infrared (FTIR) Spectroscopy. The potential application of these SS/PVA nanofibers as the drug delivery carriers was assessed by loading PCM as a model drug.

\section{Materials and Methods}

\subsection{Materials.}

Native sago starch powder (SS) and aluminum foils were purchased from the local grocery market (Kuching, Sarawak, Malaysia). Poly (vinyl alcohol) (PVA) was obtained from ACROS ORGANICS, Belgium, a syringe $(5 \mathrm{~mL})$, and syringe needle 20 gauge, the blunt tip was procured from Thomas Scientific. Ultrapure water with a resistivity of $18.2 \mathrm{M} \Omega / \mathrm{cm}$ was obtained from the Water Purifying System (ELGA, Ultra Genetic) and used throughout the experiments. Paracetamol powder (PCM) was purchased from R\&M Chemicals.

\subsection{Preparation of spinning solutions.}

The spinning solution was prepared using the blending technique, where the SS was blended into the PVA solution before the electrospinning process [29]. PVA solutions (5, 7, and 9 weight percent (w:w)) were prepared by dissolved PVA in ultrapure water at $85^{\circ} \mathrm{C}$ under constant stirring for two hours until a homogeneous solution was obtained. This PVA solution was then cooled to room temperature. Subsequently, SS was added to the PVA solution to form an SS/PVA solution with the weight ratios of 0:100, 1:100, 3:100, and 5:100 (w:w).

\subsection{Electrospinning technique.}

The electrospinning process was carried out at room temperature with the setup consisting of a Syringe Pump (New Era Pump System, Inc.), a syringe with a blunt needle (20gauge), a high voltage supply (HV350R HV REGULATED), and a sheet of aluminum foil (as the collector) which was kept at $12 \mathrm{~cm}$ from the needle tip. The applied voltage used was kept at $11 \mathrm{kV}$ [23]. The electrospinning parameters used for the fabrication of the SS/PVA nanofibers were depicted in Table 1.

\subsection{Characterization of electrospun nanofibers.}

\subsubsection{Scanning electron microscopy (SEM).}

The surface morphology of the electrospun starch nanofibers was observed using a Scanning Electron Microscope (SEM) (JEOL JSM-6390LA). The electrospun nanofibers on the aluminum foil collector were cut and placed onto the metal stubs using the carbon adhesive tape and were then coated with a thin gold layer under the vacuum before the SEM analysis was done. Then, the Smile View program was used to measure the diameter of nanofibers from the SEM micrographs, and the mean diameter of nanofibers was calculated.

\subsubsection{Water swelling ratio (WSR).}

The degree of water swelling could be described as the water absorptivity of the SS nanofibers expressed, as shown in equation (1). The dried SSSS/PVA nanofibers were weighed before immersed in $25 \mathrm{~mL}$ of ultrapure water for 24 hours at ambient temperature until the 
equilibrium was achieved. The excessed ultrapure water on the swollen nanofibers was then removed with tissue papers and weighed immediately. The weight of wet SS nanofibers at predetermined intervals was recorded during the swelling period. The swelling ratio of (WSR) of nanofibers was calculated according to equation (1):

$$
\text { WSR }=\frac{W_{1}-W_{0}}{W_{0}} x 100 \%
$$

where $\mathrm{W}_{1}$ is the weight of the swollen SS nanofibers after being centrifuged at $12000 \mathrm{rev} / \mathrm{min}$ for 10 minutes, and $\mathrm{W}_{0}$ is the weight of dried SS nanofibers samples that have been dried in the drying oven at $60{ }^{\circ} \mathrm{C}[19,30]$.

\subsection{Loading capacity of paracetamol.}

A series of PCM solutions with concentrations of $6,8,10,12$, and $14 \mathrm{mg} \mathrm{L}^{-1}$ was prepared in Phosphate Buffer Solution (PBS) at $\mathrm{pH} 7.4$ from PCM powder. Electrospun SS/PVA nanofibers were incubated in PCM solutions for 72 hours to achieve equilibrium absorption. The concentrations of PCM remained in supernatant after centrifugation was determined by a UV-visible spectrophotometer at a wavelength of $240 \mathrm{~nm}$. The drug loading capacity was calculated using equation (2):

$$
\text { Loading capacity }\left(m g \cdot \mathrm{mg}^{-1}\right)=\frac{\text { PCM }_{\text {total }}-\mathrm{PCM}_{\text {free }}}{\text { weight of nanofibers }}
$$

where PCM total is the total amount of paracetamol added to the PBS and PCM free is the amount of PCM remained in the supernatant after centrifugation.

\subsection{Release profile of paracetamol.}

2.6.1. Encapsulation of the Paracetamol into the SS/PVA nanofibers.

PCM was prepared and was added to the 1:100 (w:w) SS/PVA solution to make up the 1:100:1 (w:w:w) of SS/PVA/PCM weight ratio. This mixture was then kept under continuous stirring at room temperature for 15 minutes and used for the electrospinning.

\subsubsection{In vitro drug release.}

The amount of PCM encapsulated into SS/PVA nanofibers was predetermined [31], weighed, and then were placed in the containers filled with $10 \mathrm{~mL}$ PBS at different $\mathrm{pH}$ values of 1.2, 7.4, and 8.6. These PBS solutions mimicked the $\mathrm{pH}$ values of the stomach, blood, and large intestine, respectively. PBS solutions were used as the releasing media in an incubator at $37^{\circ} \mathrm{C}$. At predefined time intervals, $2 \mathrm{~mL}$ of PBS was withdrawn from each container and immediately replaced with the same volume of PBS. The absorbance of PBS solutions was analyzed using a UV-visible spectrophotometer at a wavelength of $240 \mathrm{~nm}$. The concentrations of PCM released were calculated by referring to the calibration curve of PCM standard solutions. The percentage of PCM release was calculated according to equation (3):

$$
\text { Drug release }(\%)=\frac{P C M_{\text {released }}}{P C M_{\text {load }}} \times 100 \%
$$

where PCM released was the amount of PCM released (mg) in the PBS, and PCM load was the amount of PCM loaded onto SS/PVA nanofibers (mg). 


\section{Results and Discussion}

\subsection{Surface morphology.}

Figures 1 illustrated the SEM micrographs of SS/PVA nanofibers fabricated with various weight ratios of SS/PVA. All nanofibers were observed to form well-defined mats of nanofibers with the diameters of nanofibers within the range of 90-150 nanometers, as shown in Figure 2. The composition of SS/PVA was observed to have a substantial effect on the morphology of the SS/PVA nanofibers formed. Figure 1 (a) and (b) showed that 5 and $7 \%$ (w:w) PVA nanofibers resulted in uneven and discontinued nanofibers with the oval-shape beads. As the concentration of PVA in the spinning solution was increased to $9 \%$ (w:w), beads free nanofibers with uniform diameter were obtained (Figure 1c). On the other hand, Figures 1 (d), (e), and (f) showed SEM micrographs of nanofibers from SS/PVA with a weight ratio of 1:100, 3:100, and 5:100 (w:w), respectively. The effect of SS concentration with fixed PVA concentration on the mean diameter of nanofibers formed, as shown in Figure 1 (b). As the weight ratio of SS/PVA solution increased from 1:100 to 5:100 (w:w) in the fixed concentration of $9 \%(\mathrm{w}: \mathrm{w})$ of PVA, the mean diameter of the nanofibers was observed to increase from 90 $\mathrm{nm}$ to $140 \mathrm{~nm}$. The smallest nanofibers diameter of $91 \mathrm{~nm}$ was produced from SS/PVA solution of 1:100 (w:w) weight ratio. Figure $1(\mathrm{~g})$ showed uniform and smooth SS/PVA/PCM nanofibers were formed from SS/PVA/PCM solution with a volume ratio of 1:100:1 (w:w). Bead-free SS/PVA nanofibers only produced when 9\% (w:w) of the PVA solution was used. Thus, 9\% (w:w) of the PVA solution was considered for further optimization of SS/PVA electrospinning.

The concentration of PVA was a crucial parameter in which it was directly related to viscosity, surface tension, and viscoelastic force of the polymer solution. The formation of beaded nanofibers at lower PVA concentrations was attributed to the changes in viscosity of the solution. The viscosity is associated with the degree of polymer chain molecules entanglement within a PVA solution [12]. An increase in polymer chain entanglement because of the increase in the number of polymer molecules increased its viscosity [32]. The low viscosity of PVA solution having a low viscoelastic force was not able to compensate for the electrostatic repulsion forces that pulled the PVA solution jet during the electrospinning process and led to the jet partially broke up. By the effect of interfacial tension, the high numbers of free solvent molecules in the solution combined into a spherical shape, which resulted in the formation of beads [33]. Once the concentration of PVA was increased, the viscosity of the solution also increased and resulted in an enhanced viscoelastic force. This had prevented the jet from partially broke up. The increased polymer chain entanglement with higher solution concentration also enabled the solvent molecules to be distributed over the entangled polymer molecules, led to the formation of smooth fibers, and improved the nanofiber uniformity [34].

As can be observed from Table 1, feed rates and applied voltages were varied while the SS/PVA weight ratios and tip to collector distance were kept constant. The feed rate of $1.2 \mathrm{ml} / \mathrm{h}$ was observed to produce SS/PVA nanofibers with beads with a mean diameter size of 110 to $145 \mathrm{~nm}$. Table 2 showed that the collector distance did not affect much the diameter size of nanofibers. Besides, there were no significant differences in nanofibers morphology for various distances. The same findings have been reported for the electrospinning of gelatin, chitosan, poly(vinyl alcohol), and poly(vinylidene fluoride) [35,36] nanofibers. Whereas, when a low concentration of a spinning solution (5\% and 7\% (w:w) PVA at $0 \%(\mathrm{w}: \mathrm{w})$ of SS) was used, 
beaded nanofibers were observed to form. The viscosity of SS/PVA solution was observed to be a crucial factor that determined the spinnability of this polymer, which resulted in the entanglement of the polymer molecules and the formation of a continuous jet of polymer solution instead of droplets, which led to the formation of beads in nanofiber [37]. Nonetheless, a very high viscosity has caused the polymer solution to distort the flow of spinning solution across the passageway of the needle that gave rise to the formation of a localized gel that inhibited the production of nanofibers [38]. Therefore, a 9\% (w:w) of the PVA solution was chosen to be used for the optimization of the process.
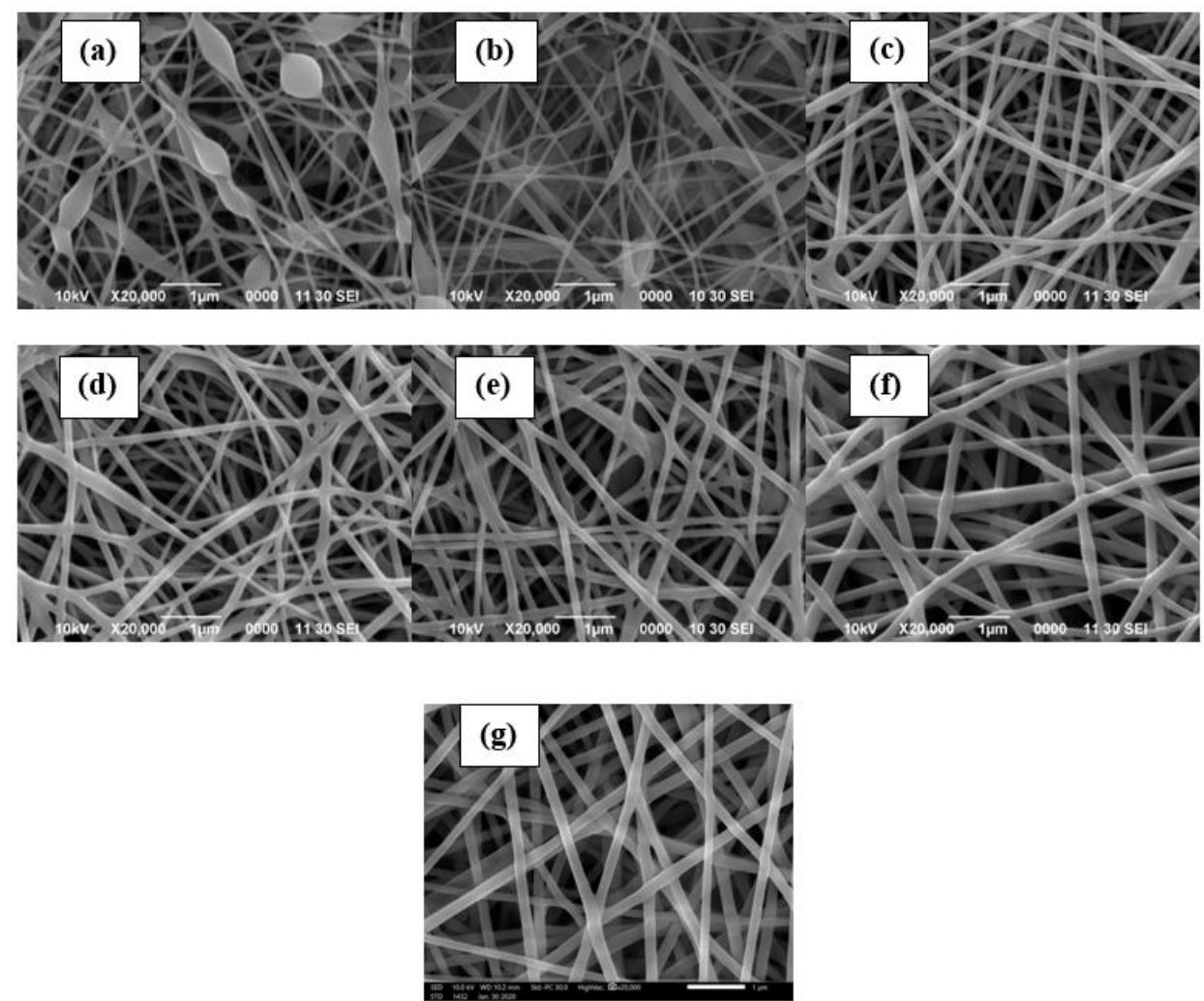

Figure 1. SEM micrographs of nanofibers fabricated with SS/PVA weight ratio; 0:100 of (a) 5\% (w:w) PVA (b) 7\% (w:w) PVA (c) 9\% (w:w) PVA; $9 \%$ (w:w) PVA (d) 1:100 (w:w), (e) 3:100 (w:w), (f) 5:100 (w:w); and (g) SS/PVA/PCM ratio of 1:100:1 (w:w).

Table 1. Effects of voltages and feed rates on the morphology of nanofibers.

\begin{tabular}{|c|c|c|c|}
\hline \multicolumn{2}{|c|}{ Electrospinning parameters } & \multirow{2}{*}{ Fiber mean diameter $(\mathbf{n m})$} & \multirow{2}{*}{ Fiber morphology } \\
\hline Feed rate $(\mathrm{mL} / \mathrm{h})$ & Voltage $(\mathrm{kV})$ & & \\
\hline \multirow{4}{*}{0.6} & 5 & 145 & Bead -free \\
\hline & 7 & 125 & Bead -free \\
\hline & 9 & 116 & Bead -free \\
\hline & 11 & 117 & Bead-free \\
\hline \multirow{4}{*}{0.8} & 5 & 145 & Bead-free \\
\hline & 7 & 123 & Bead-free \\
\hline & 9 & 119 & Bead-free \\
\hline & 11 & 128 & Bead-free \\
\hline \multirow{4}{*}{1.0} & 5 & 115 & Bead-free \\
\hline & 7 & 111 & Bead-free \\
\hline & 9 & 124 & Bead-free \\
\hline & 11 & 91 & Bead-free \\
\hline \multirow{4}{*}{1.2} & 5 & 113 & Beaded \\
\hline & 7 & 93 & Beaded \\
\hline & 9 & 89 & Beaded \\
\hline & 11 & 95 & Beaded \\
\hline
\end{tabular}


Table 2. Effect of the tip to collector distance on the morphology of SS/PVA nanofibers.

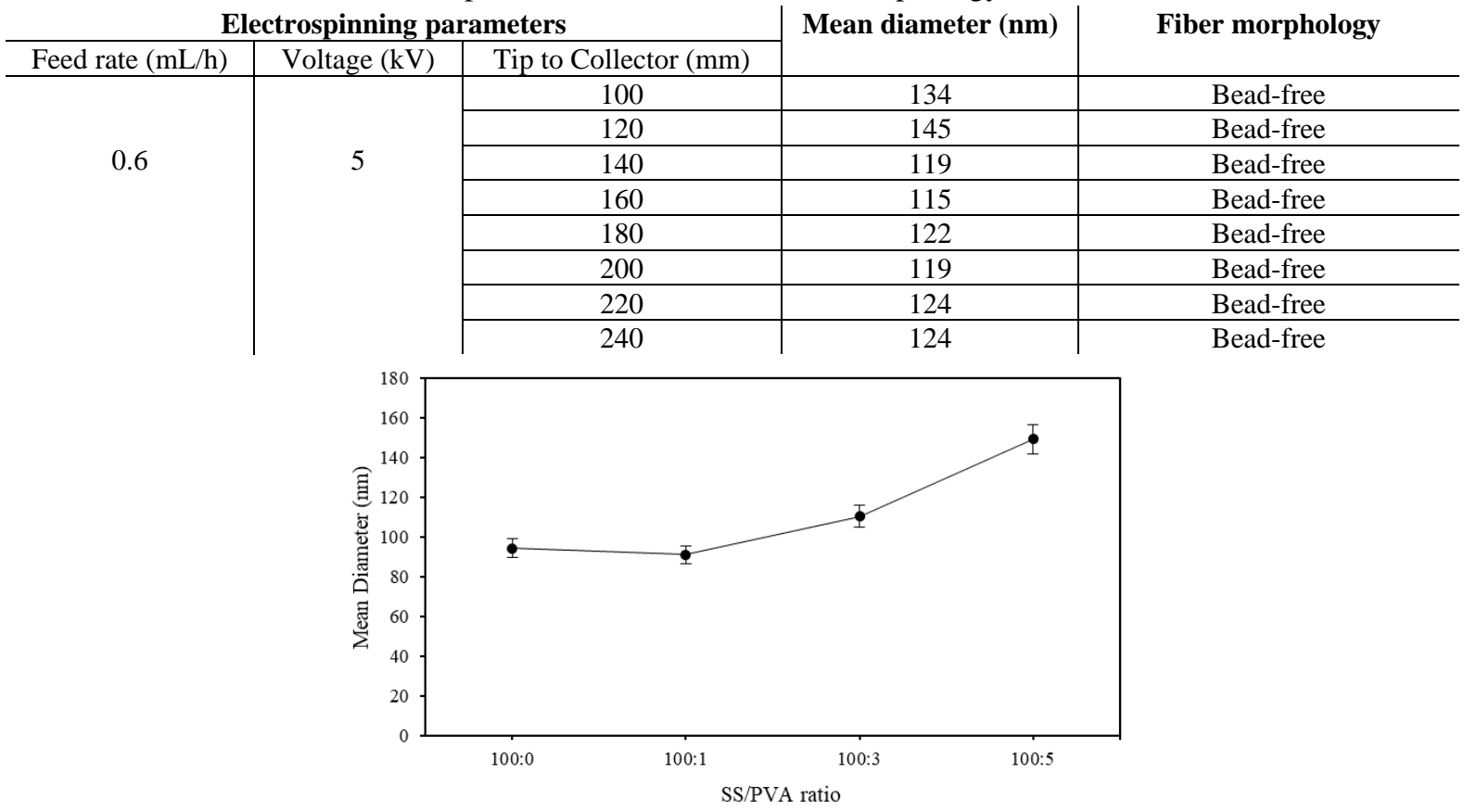

Figure 2. Mean diameters of nanofibers fabricated with 9\% (w:w) PVA at SS/PVA weight ratio of 0:100, 1:100, $3: 100,5: 100$.

\subsection{Water swelling ratio (WSR).}

Figure 3 showed the effects of the mean diameter size of SS/PVA electrospun nanofibers on its WSR. It could be seen that the WSR of the nanofibers at the highest of $400 \%$ with the mean diameter size of $94 \mathrm{~nm}$. While the lowest WSR is at $80 \%$ was achieved with 140 nm mean diameter size of nanofibers. Considering the morphology of the nanofibers, as shown in Figure 1 (d), (e), and (f), the increase in SS concentration has resulted in the increased mean diameter of nanofibers formed and led to a decrease in their WSR (Figure 3). In a similar study, Perves and Stylios also reported on the smallest sizes of fibers could produce a high swelling ratio compared to the largest size of fibers [39]. This is because the smaller fibers have a larger surface area to volume ratio allow them to possess a higher adsorption capacity. However, the cross-linked nanofibers have the same capability of decreasing water absorption to a great extent, which resulted in maintaining a stable fibrous structure in wet conditions. Also, the cross-linking was able to reduce the hydrophilicity, as well as the formation of intramolecular and intermolecular bonds between PVA macromolecular chains and water-soluble polymer [40].

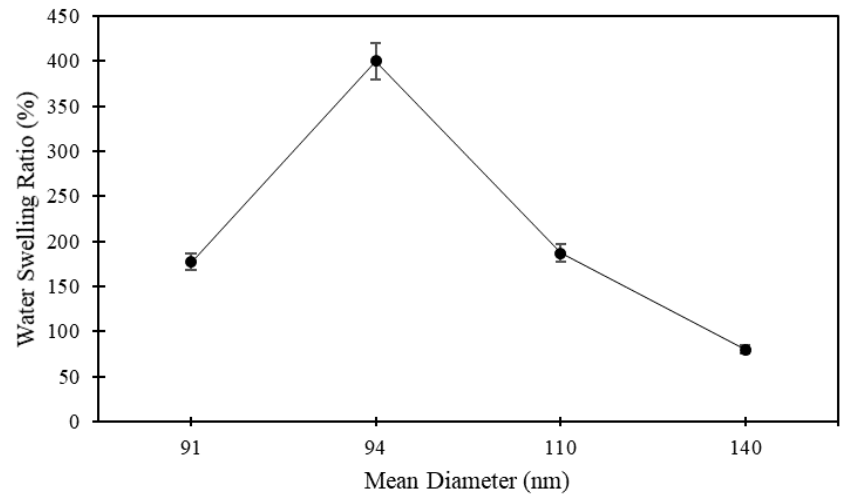

Figure 3. The effects of the various diameter of SS/PVA on the swelling water ratio (\%). 
3.3. Drug loading capacity and release profile of sago starch nanofibers.

\subsubsection{Drug loading capacity.}

As shown in Figure 4, the PCM loading capacity of SS/PVA nanofibers was observed to increase with PCM concentrations. The highest loading capacity of $0.9573 \mathrm{mg}^{\mathrm{mg}}{ }^{-1}$ was at $12 \mathrm{mg} . \mathrm{L}^{-1}$. Meanwhile, the lowest loading capacity was achieved by the SS/PVA was at $6 \mathrm{mg} . \mathrm{L}^{-}$ ${ }^{1}$, which is $0.6843 \mathrm{mg}^{-\mathrm{mg}^{-1}}$. Besides, the loading capacity was observed to increase between $0.6843 \mathrm{mg} \cdot \mathrm{mg}^{-1}$ to $0.9573 \mathrm{mg} \cdot \mathrm{mg}^{-1}$ from $6 \mathrm{mg} . \mathrm{L}^{-1}, 8 \mathrm{mg} . \mathrm{L}^{-1}, 10 \mathrm{mg} . \mathrm{L}^{-1}$ and $12 \mathrm{mg} . \mathrm{L}^{-1}$ with $0.6843 \mathrm{mg} \cdot \mathrm{mg}^{-1}, 0.7658 \mathrm{mg} \cdot \mathrm{mg}^{-1}, 0.8621 \mathrm{mg} \cdot \mathrm{mg}^{-1}$ and $0.9573 \mathrm{mg} \cdot \mathrm{mg}^{-1}$ respectively. This finding showed that starch nanofibers have high potential as the paracetamol nanocarriers, as evidenced by its high loading capacity. According to previous studies, the loading capacity of paracetamol onto nanoparticles can be increased by increasing the concentration of paracetamol. The maximum loading capacity of $5.00 \mathrm{mg} \cdot \mathrm{mg}^{-1}$ was obtained when the concentration of paracetamol was increased to $10 \mathrm{mg} . \mathrm{L}^{-1}$ [41]. This was because smaller size nanoparticles have a higher surface area to volume ratios, which could enhance its loading capacity of the drug [42]. Their finding showed that the loading capacity of starch nanoparticles could be enhanced by increasing the concentration of paracetamol. However, above $12 \mathrm{mg} . \mathrm{L}^{-1}$ of paracetamol concentration, the loading started to drop due to the presence of a high concentration of paracetamol, which could be caused by the highly viscous solution $[43,44]$. Therefore, the optimal loading capacity of $0.95732 \mathrm{mg}^{-\mathrm{mg}^{-1}}$ can be achieved at a paracetamol concentration of $12 \mathrm{mg} \cdot \mathrm{L}^{-1}$.

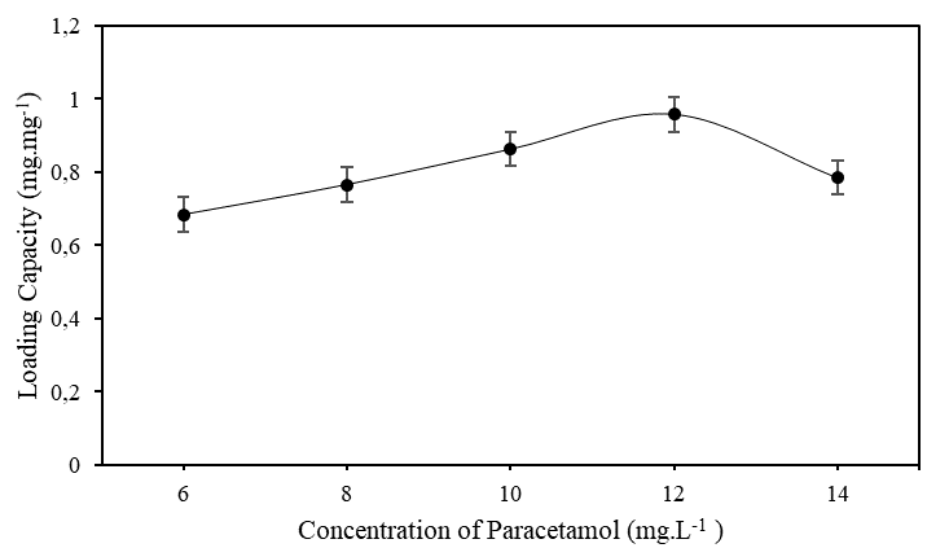

Figure 4. The loading capacity of 100:1 weight ratio of 9\% (w:w) PVA 1\% (w:w) SS at different concentrations of PCM.

\subsubsection{Drug release study.}

Figure 5 showed the release profiles of PCM from the SS nanofibers at $\mathrm{pH} 1.2,7.4$, and 8.6 fabricated with blending technique with the PCM being encapsulated inside the nanofibers. This method is the most common method of drug incorporation by which the drug is dissolved in a polymer solution and the producing drug-loaded electrospun nanofibers [45]. The PCM was mixed with the spinning polymer (SS/PVA) before the electrospinning process. As can be observed from Figure 5, there was no significant difference in the percentage release of PCM at three different $\mathrm{pH}$ values for the initial four hours. PCM was released rapidly at all pHs and then gradually declined with progress in time. Beyond four hours of experiment, a clear difference in the percentage of release could be observed. The amount of PCM released from SS/PVA nanofibers was observed to be the highest at $\mathrm{pH} 8.6$, followed by at $\mathrm{pH} 7.4$ and $\mathrm{pH}$ 
1.2. The percentage of release was observed to level off after 44 hours at all of the $\mathrm{pH}$ values. Thus, $\mathrm{pH} 1.2$ displayed the slowest release rate within a duration of 8 to 72 hours as compared to $\mathrm{pH} 7.4$ and 8.6, respectively, due to the acidic medium that could cause the hydrogen bonding to become stronger between the drug and the polymers [46]. Besides, it was reported that hydrogen bond interactions could cause drug release to release gradually [47].

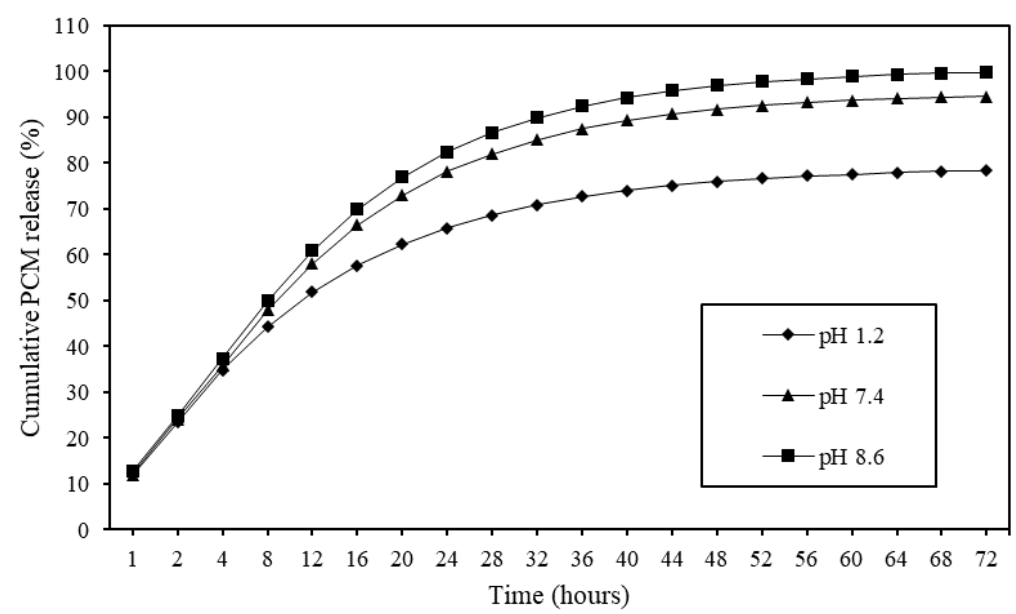

Figure 5. The cumulative PCM was released from SS/PVA nanofibers at different $\mathrm{pH}$ media $(1.2,7.4$, and 8.6) as a function of time.

\section{Conclusions}

In conclusion, we have successfully fabricated smooth and bead-free starch-based nanofibers through a simple electrospinning technique. Apart from the electrospinning technique process setup, the composition of the SS/PVA spinning solution was observed to be the crucial parameter for producing the smooth and uniform SS/PVA nanofibers. As the weight ratio of SS/PVA increased from 1:100, 3:100, and 5:100 (w:w), thus the mean diameter of nanofibers formed has also increased from 91 to $149 \mathrm{~nm}$. The optimum concentration of $9 \%$ (w:w) PVA produced bead free, smooth, and uniform nanofibers. PCM was observed to be released from the SS/PVA nanofibers in a sustained manner for 72 hours.

\section{Funding}

This research was funded by the Malaysia Ministry of Higher Education, Fundamental Research Grant Scheme (F07/FRGS/1495/2016).

\section{Acknowledgments}

The authors gratefully acknowledge the financial support rendered by the Malaysia Ministry of Higher Education, Fundamental Research Grant Scheme (F07/FRGS/1495/2016).

\section{Conflicts of Interest}

The authors declare no conflict of interest.

\section{References}

1. Alghoraibi, I.; Alomari, S. Different Methods for Nanofiber Design and Fabrication. In: Handbook of Nanofibers. Barhoum, A.; Bechelany, M.; Makhlouf, A. Eds.; Springer International Publishing: Cham, 2018; pp. 1-46. 
2. Zhang, L.; Tang, Y.; Tong, L. Micro-/Nanofiber Optics: Merging Photonics and Material Science on Nanoscale for Advanced Sensing Technology. iScience 2020, 23, https://doi.org/10.1016/j.isci.2019.100810.

3. Kong, Y.Y.; Pang, S.C.; Chin, S.F. Facile synthesis of nickel nanowires with controllable morphology. Mater. Lett. 2015, 142, 1-3, https://doi.org/10.1016/j.matlet.2014.11.140.

4. Bhardwaj, N.; Kundu, S.C. Electrospinning: A fascinating fiber fabrication technique. Biotechnol. Adv. 2010, 28, 325-347, https://doi.org/10.1016/j.biotechadv.2010.01.004.

5. Bhagwan, J.; Kumar, N.; Sharma, Y. Fabrication, Characterization, and Optimization of Mn O Nanofibers for Improved Supercapacitive Properties. In: Nanomaterials Synthesis; Elsevier, 2019; pp. 451-481, https://doi.org/10.1016/B978-0-12-815751-0.00013-4.

6. Moheman, A.; Alam, M.S.; Mohammad, A. Recent trends in electrospinning of polymer nanofibers and their applications in ultra thin layer chromatography. Advances in Colloid and Interface Science 2016, 229, 1-24, https://doi.org/10.1016/j.cis.2015.12.003.

7. Hu, X.; Liu, S.; Zhou, G.; Huang, Y.; Xie, Z.; Jing, X. Electrospinning of polymeric nanofibers for drug delivery applications. J. Controlled Release 2014, 185, 12-21, https://doi.org/10.1016/j.jconrel.2014.04.018.

8. Li, D.; Xia, Y. Electrospinning of Nanofibers: Reinventing the Wheel? Adv. Mater. 2004, 16, 1151-1170.

9. Jaiturong, P.; Sirithunyalug, B.; Eitsayeam, S.; Asawahame, C.; Tipduangta, P.; Sirithunyalug, J. Preparation of glutinous rice starch/polyvinyl alcohol copolymer electrospun fibers for using as a drug delivery carrier. Asian Journal of Pharmaceutical Sciences 2018, 13, 239-247, https://doi.org/10.1016/j.ajps.2017.08.008.

10. Zhang, L. Electrospun PEGylated PLGA nanofibers for drug encapsulation and release. Mater. Sci. $2018,8$.

11. Liu, G.; Gu, Z.; Hong, Y.; Cheng, L.; Li, C. Electrospun starch nanofibers: Recent advances, challenges, and strategies for potential pharmaceutical applications. J. Controlled Release 2017, 252, 95-107, https://doi.org/10.1016/j.jconrel.2017.03.016.

12. Deitzel, J.M.; Kleinmeyer, J.; Harris, D.; Beck Tan, N.C. The effect of processing variables on the morphology of electrospun nanofibers and textiles. Polymer 2001, 42, 261-272, https://doi.org/10.1016/S0032-3861(00)00250-0.

13. Rutledge, G.C.; Fridrikh, S.V. Formation of fibers by electrospinning. Advanced Drug Delivery Reviews 2007, 59, 1384-1391, https://doi.org/10.1016/j.addr.2007.04.020.

14. Tipduangta, P.; Belton, P.; Fábián, L.; Wang, L.Y.; Tang, H.; Eddleston, M.; Qi, S. Electrospun Polymer Blend Nanofibers for Tunable Drug Delivery: The Role of Transformative Phase Separation on Controlling the Release Rate. Mol. Pharm. 2016, 13, 25-39, https://doi.org/10.1021/acs.molpharmaceut.5b00359.

15. Jiang, Y.-N.; Mo, H.-Y.; Yu, D.-G. Electrospun drug-loaded core-sheath PVP/zein nanofibers for biphasic drug release. Int. J. Pharm. 2012, 438, 232-239, https://doi.org/10.1016/j.ijpharm.2012.08.053.

16. Das, S.; Roy, S.; Yuvaraja, K.; Khanam, J.; Nanda, A. Solid Dispersions : An Approach to Enhance the Bioavailability of Poorly Water-Soluble Drugs. Int J Pharmacol Pharma Technol 2011, 1.

17. Fonseca, L.M.; Cruxen, C.E.d.S.; Bruni, G.P.; Fiorentini, Â.M.; Zavareze, E.d.R.; Lim, L.-T.; Dias, A.R.G. Development of antimicrobial and antioxidant electrospun soluble potato starch nanofibers loaded with carvacrol. Int. J. Biol. Macromol. 2019, 139, 1182-1190, https://doi.org/10.1016/j.ijbiomac.2019.08.096.

18. Xu, W.; Yang, W.; Yang, Y. Electrospun starch acetate nanofibers: development, properties, and potential application in drug delivery. Biotechnol Prog 2009, 25, 1788-1795.

19. Sutjarittangtham, K.; Jaiturong, P.; Intatha, U.; Pengpat, K.; Eitssayeam, S.; Sirithunyalug, J. Fabrication of Natural Tapioca Starch Fibers by a Modified Electrospinning Technique. Chiang Mai Journal of Science 2014, 41, 213-223.

20. Ainurofiq, A.; Choiri, S. Drug Release Mechanism of Slightly Soluble Drug from Nanocomposite Matrix Formulated with Zeolite/ Hydrotalcite as Drug Carrier. Trop. J. Pharm. Res. 2015, 14, https://doi.org/10.4314/tjpr.v14i7.2.

21. Cárdenas, W.; Gómez-Pachon, E.Y.; Muñoz, E.; Vera-Graziano, R. Preparation of potato starch microfibers obtained by electro wet spinning. IOP Conf. Ser. Mater. Sci. Eng. 2016, 138, https://doi.org/10.1088/1757899X/138/1/012001.

22. Kong, L.; Ziegler, G.R. Fabrication of pure starch fibers by electrospinning. Food Hydrocoll. 2014, 36, 2025, https://doi.org/10.1016/j.foodhyd.2013.08.021.

23. Wang, W.; Jiang, S.; Jiang, S.; Zhai, L.; Jiang, Q. Poly(vinyl alcohol)/Oxidized Starch Fibres via Electrospinning Technique: Fabrication and Characterization. Iranian Polymer Journal (English Edition) 2011, 20.

24. Wang, H.; Kong, L.; Ziegler, G.R. Aligned wet-electrospun starch fiber mats. Food Hydrocoll. 2019, 90 , 113-117, https://doi.org/10.1016/j.foodhyd.2018.12.008.

25. Pang, S.C.; Tay, S.H.; Chin, S.F. Facile Synthesis of Curcumin-Loaded Starch-Maleate Nanoparticles. J. Nanomater. 2014, 2014, 1-7, https://doi.org/10.1155/2014/824025.

26. Rostamabadi, H.; Falsafi, S.R.; Jafari, S.M. Starch-based nanocarriers as cutting-edge natural cargos for nutraceutical delivery. Trends Food Sci. Technol. 2019, 88, 397-415, https://doi.org/10.1016/j.tifs.2019.04.004.

27. Supaphol, P.; Chuangchote, S. On the electrospinning of poly(vinyl alcohol) nanofiber mats: A revisit. $J$. Appl. Polym. Sci. 2008, 108, 969-978. 
28. Pang, S.C.; Chin, S.F.; Tay, S.H.; Tchong, F.M. Starch-maleate-polyvinyl alcohol hydrogels with controllable swelling behaviors. Carbohydr. Polym. 2011, 84, 424-429, https://doi.org/10.1016/j.carbpol.2010.12.002.

29. Šukytė, J.; Adomavičiūtè, E.; Milašius, R. Investigation of the Possibility of Forming Nanofibres with Potato Starch. Fibres \& Textiles in Eastern Europe. 2010, Vol. 18, No. 5 (82) pp. 24-27.

30. Lu, P.-P.; Xu, Z.-L.; Yang, H.; Wei, Y.-M.; Xu, H.-T. Effects of ethanol and isopropanol on the structures and properties of polyethersulfone/perfluorosulfonic acid nanofibers fabricated via electrospinning. J. Polym. Res. 2012, 19, 9854, doi:10.1007/s10965-012-9854-0.

31. Liu, M.; Duan, X.-P.; Li, Y.-M.; Yang, D.-P.; Long, Y.-Z. Electrospun nanofibers for wound healing. Mater. Sci. Eng. C 2017, 76, 1413-1423, https://doi.org/10.1016/j.msec.2017.03.034.

32. Al-Karawi, A.J.M.; Al-Daraji, A.H.R. Preparation and using of acrylamide grafted starch as polymer drug carrier. Carbohydr. Polym. 2010, 79, 769-774, https://doi.org/10.1016/j.carbpol.2009.10.003.

33. Sa'adon, S.; Abd Razak, S.I.; Ismail, A.E.; Fakhruddin, K. Drug-Loaded Poly-Vinyl Alcohol Electrospun Nanofibers for Transdermal Drug Delivery: Review on Factors Affecting the Drug Release. Procedia Comput. Sci. 2019, 158, 436-442, https://doi.org/10.1016/j.procs.2019.09.073.

34. Tungprapa, S.; Puangparn, T.; Weerasombut, M.; Jangchud, I.; Fakum, P.; Semongkhol, S.; Meechaisue, C.; Supaphol, P. Electrospun cellulose acetate fibers: effect of solvent system on morphology and fiber diameter. Cellulose 2007, 14, 563-575, https://doi.org/10.1007/s10570-007-9113-4.

35. Tarus, B.; Fadel, N.; Al-Oufy, A.; El-Messiry, M. Effect of polymer concentration on the morphology and mechanical characteristics of electrospun cellulose acetate and poly (vinyl chloride) nanofiber mats. Alex. Eng. J. 2016, 55, 2975-2984, https://doi.org/10.1016/j.aej.2016.04.025.

36. Mit-uppatham, C.; Nithitanakul, M.; Supaphol, P. Ultrafine Electrospun Polyamide-6 Fibers: Effect of Solution Conditions on Morphology and Average Fiber Diameter. Macromol. Chem. Phys. 2004, 205, 23272338, https://doi.org/10.1002/mame.200500024.

37. Pham, Q.P.; Sharma, U.; Mikos, A.G. Electrospinning of Polymeric Nanofibers for Tissue Engineering Applications: A Review. Tissue Engineering 2006, 12, 1197-1211, https://doi.org/10.1089/ten.2006.12.1197.

38. Motamedi, A.S.; Mirzadeh, H.; Hajiesmaeilbaigi, F.; Bagheri-Khoulenjani, S.; Shokrgozar, M. Effect of electrospinning parameters on morphological properties of PVDF nanofibrous scaffolds. Prog. Biomater. 2017, 6, 113-123, https://doi.org/10.1007/s40204-017-0071-0.

39. Jiang, S.; Lv, L.-P.; Landfester, K.; Crespy, D. Nanocontainers in and onto Nanofibers. Acc. Chem. Res. 2016, 49, 816-823, https://doi.org/10.1021/acs.accounts.5b00524.

40. Zong, X.; Kim, K.; Fang, D.; Ran, S.; Hsiao, B.S.; Chu, B. Structure and process relationship of electrospun bioabsorbable nanofiber membranes. Polymer 2002, 43, 4403-4412, https://doi.org/10.1016/S00323861(02)00275-6.

41. Pervez, M.; Stylios, G. Investigating the Synthesis and Characterization of a Novel "Green" $\mathrm{H}_{2} \mathrm{O}_{2}-\mathrm{Assisted}$ Water-Soluble Chitosan/Polyvinyl Alcohol Nanofiber for Environmental End Uses. Nanomaterials 2018, 8, https://doi.org/10.3390/nano8060395.

42. Yuan, Y.; Chesnutt, B.M.; Utturkar, G.; Haggard, W.O.; Yang, Y.; Ong, J.L.; Bumgardner, J.D. The effect of cross-linking of chitosan microspheres with genipin on protein release. Carbohydr. Polym. 2007, 68, 561567, https://doi.org/10.1016/j.carbpol.2006.10.023.

43. Chin, S.F.; Romainor, A.N.B.; Pang, S.C.; Lee, B.K.; Hwang, S.S. pH-Responsive Starch-Citrate Nanoparticles for Controlled Release of Paracetamol. Starch-Stärke 2019, 71, 1800336, https://doi.org/10.1002/star.201800336.

44. Rizvi, S.A.A.; Saleh, A.M. Applications of nanoparticle systems in drug delivery technology. Saudi Pharm. J. 2018, 26, 64-70, https://doi.org/10.1016/j.jsps.2017.10.012.

45. Chin, S.F.; Mohd Yazid, S.N.A.; Pang, S.C. Preparation and Characterization of Starch Nanoparticles for Controlled Release of Curcumin. Int. J. Polym. Sci. 2014, 2014, 1-8, https://doi.org/10.1155/2014/340121.

46. Chong W.H,; Chin. S.F,; C.; Pang, S.C.; Kok, K.Y. Synthesis and Characterisation of Piperine-loaded Starch Nanoparticles. J. Phys. Sci. 2020, 31, 57-68, https://doi.org/10.21315/jps2020.31.1.4.

47. Goonoo, N.; Bhaw-Luximon, A.; Jhurry, D. Drug Loading and Release from Electrospun Biodegradable Nanofibers. J. Biomed. Nanotechnol. 2014, 10, 2173-2199, https://doi.org/10.1166/jbn.2014.1885.

48. Gilli, P.; Pretto, L.; Bertolasi, V.; Gilli, G. Predicting Hydrogen-Bond Strengths from Acid-Base Molecular Properties. The p $K_{\text {a }}$ Slide Rule: Toward the Solution of a Long-Lasting Problem. Acc. Chem. Res. 2009, 42, 33-44, https://doi.org/10.1021/ar800001k.

49. Chin, S.F.; Salim, A.; Pang, S.C. Hydroxypropyl Starch Nanoparticles as Controlled Release Nanocarriers for Piperine. J Nanostruct 2020, 10, 327-336, https://doi.org/10.22052/JNS.2020.02.01 